\title{
Child, family, school and community risk factors for poor mental health in Brazilian schoolchildren
}

Anna Goodman ${ }^{1}$, Bacy Fleitlich-Bilyk ${ }^{2}$, Vikram Patel ${ }^{1}$, Robert Goodman ${ }^{3}$

1 London School of Hygiene \& Tropical Medicine, London, UK

2 Department of Psychiatry, University of São Paulo, Brazil

3 King's College London Institute of Psychiatry, London, UK

Corresponding author: Anna Goodman, London School of Hygiene \& Tropical Medicine, Keppel Street, London, WC1E 7HT, UK (anna.goodman@1shtm.ac.uk).

Note: this is a personal version, created by Anna Goodman, of the text of the accepted journal article. It reflects all changes made in the peer review process, but does not incorporate any minor modifications made at the proof stage. The complete citation for the final journal article is:

- Goodman A, Fleitlich-Bilyk B, Patel V, Goodman R. Child, family, school and community risk factors for poor mental health in Brazilian schoolchildren. J Am Acad Child Adolesc Psychiatry. 2007;46(4):448-56.

- DOI: 10.1097/chi.0b013e31803065b5

Copyright (C) and Moral Rights for this paper are retained by the individual authors and/or other copyright owners 


\begin{abstract}
$\underline{\text { Abstract }}$
Objective: To identify risk factors for poor child mental health in the south-eastern Brazilian municipality of Taubaté

Method: In 2001 we carried out a representative school-based survey of Brazilian schoolchildren aged 7-14 years (response rate 83\%). We collected extensive data on child mental health and on potential risk and protective factors at baseline $(\mathrm{N}=1112)$ and collected follow-up information on mental health outcome after three years $(\mathrm{N}=760)$. We used the Strengths and Difficulties Questionnaire as a dimensional measure of mental health at both time points and the Development and Well-Being Assessment to diagnose psychiatric disorder at baseline.

Results: Cross-sectionally, both dimensional and diagnostic measures of child psychopathology were associated with dangerous area, non-traditional family, parental stress, harsh physical punishment, poor general health, low IQ, repeating a year at school and male gender. There were different cross-sectional associations with different types of psychopathology. Psychological difficulties were moderately persistent across time. Younger age, lower maternal education and lower child's IQ predicted a worse prognosis even after adjusting for initial psychopathology.
\end{abstract}

Conclusion: The multiple factors associated with Brazilian child mental health are broadly in line with previous findings elsewhere. Public health programmes to foster child mental health need multiple targets, but may benefit a wide range of the population.

Key Words: Child; Adolescent; Mental health; Risk factors; Developing Countries. 


\section{$\underline{\text { Introduction }}$}

The great majority of the world's children and adolescents live in low- and middleincome countries, where children and adolescents make up a higher proportion of the population than in high-income countries. What little high-quality research has been done suggests that child psychiatric disorders affect 10-20\% of children in these countries (Bird et al., 1988; Canino et al., 2004; Fleitlich-Bilyk and Goodman, 2004; Hackett and Hackett, 1999; Hackett et al., 1999).

Ascertaining the risk factors for psychiatric disorder is important for understanding the etiology of childhood psychopathology and for identifying potential targets for prevention and intervention. Little is known, however, about the predictors of poor mental health in low- and middle-income countries (Hackett and Hackett, 1999; Remschmidt and Belfer, 2005).. Moreover, all studies to date in low- and middle-income countries have provided data on cross-sectional associations only, which can make it difficult to decide what is causaing what. A prospective study following children over time provides more information on the likely direction of causal relationships, although in the absence of randomisation the problems of potential confounding remain.

What research has been done indicates more commonalities than differences between the determinants of child mental health in less affluent countries and those long established in high-income countries (Hackett and Hackett, 1999). In terms of individual-level predictors of poor mental health, males are at greater risk of externalizing problems and females of internalizing problems (Canino et al., 2004; Hackett and Hackett, 1999). Poor physical health has repeatedly been shown to be associated with poor mental health, particularly emotional disorders (Hackett and Hackett, 1999). There is also some evidence that malnutrition, perinatal complications, and infections of the central nervous system can play a role, although the evidence on all these factors is patchy and hard to interpret (Hackett and Hackett, 1999). Psychological and educational factors such as low intelligence and school failure are powerful predictors of poor mental health in all lowand middle-income settings in which they have been examined (Hackett and Hackett, 1999; Hackett et al., 1999). Experiencing adverse life events such as bereavement and parental divorce has also been found to be an important predictor of poor child mental health (Hackett and Hackett, 1999; Hackett et al., 2000).

In addition to the individual-level variables outlined above, several important family risk factors have been identified. Stress or mental illness in the parents has consistently been found to be associated with child psychopathology (Hackett and Hackett, 1999; Vitolo et al., 2005), as well as in our own preliminary work in Brazil (Fleitlich and Goodman, 2001). Parenting methods and family functioning also play a key role, with poor family discipline, the use of physical punishment, parental disharmony and witnessing marital violence all identified as powerful risk factors (Hackett and Hackett, 1999; Patel et al., In Press; Vitolo et al., 2005). Family composition also appears important. For example, having cohabiting as opposed to married parents was found to be a significant risk factor for emotional disorders in Puerto Rico (Canino et al., 2004). Whether a family is extended or not also seems to have different implications in different settings, being 
sometimes protective, sometimes neutral, and sometimes a risk factor (Hackett and Hackett, 1999).

Socio-economic status and parental education are inversely associated with psychiatric disorder in a majority of studies (Hackett and Hackett, 1999; Hackett et al., 1999). School and community factors may also be important. For example, a zero tolerance policy towards bullying in schools and high levels of social capital in communities have been suggested as protective factors (Mullick and Goodman, 2005; Patel et al., In Press), while transitions such as urbanization have been suggested as risk factors (Hackett and Hackett, 1999; Patel et al., In Press). Caution is needed in interpreting these findings, however, as few studies have collected high quality data on these factors, and those which have done so have often failed to model information about communities, schools, families and individual children simultaneously.

The importance of considering different sorts of risk factors simultaneously is highlighted by our own preliminary study in Brazil, in which living in a favela (shantytown) was associated with a particularly high rate of child mental health problems in univariate analyses, but was no longer predictive once allowance was made for parental social class, education, maternal depression, marital violence and use of harsh physical punishment (Fleitlich and Goodman, 2001).

We conducted a survey of a representative group of schoolchildren aged 7-14 years in Brazil, Latin America's largest and most populous country, in order to identify risk factors for poor child mental health in this setting. Our study included both a crosssectional and a longitudinal component, and collected detailed information on the characteristics of children, families, neighborhoods and schools, allowing simultaneous investigation of the interrelationships between different characteristics, and their associations with childhood psychiatric disorder. Risk factor and outcome data were deliberately collected in a way which maximizes comparability with the British Child and Adolescent Mental Health Surveys (B-CAMHS) of 1999 and 2004 (Ford et al., 2004; Green et al., 2005) in order to facilitate exploration of the extent to which findings in high-income settings can be generalized to low- and middle-income countries.

\section{Method}

\section{Setting, Procedures and Participants}

This school-based cross-sectional and longitudinal study was carried out in Taubaté, a municipality in the southeast of Brazil of approximately 220,000 people living in a medium-sized city and its surrounding rural areas. About 96\% of the 7-14 year olds attend school. A detailed account of the Taubate study's strategy, procedures, subjects and measures of psychopathology has been published elsewhere (Fleitlich-Bilyk and Goodman, 2004). Briefly, the original study was a two-stage cross-sectional survey with stratification by school type. The two stages were random sampling of schools, stratified into private schools, public rural schools and public urban schools, followed by random sampling of pupils from within schools. In total, 1251 (83\%) of the 1504 children randomly selected from school registers participated (see Figure 1), a proportion which 
did not vary by school type (Fleitlich-Bilyk and Goodman, 2004). Private and rural schools were relatively oversampled, with the aim of ensuring that approximately $20 \%$ of the achieved sample came from each of these categories. The private, rural and urban school types mirror the three primary social groupings in Brazil; namely the affluent middle-class, the rural poor and the urban poor. After a mean interval of 2.88 years (SD 0.67 years), we sought to collect follow-up information on child mental health for all 1251 children included in the original study (Figure 1). Ethical approval for the procedures was obtained from the Institutes of Psychiatry in São Paulo and London. Informed consent was obtained from parents for their participation in the project, and for approaching their child and their child's teacher for participation.

Figure 1: Participant flow chart for the Taubate study

From school list:

28 schools approached, 26 agreed to participate
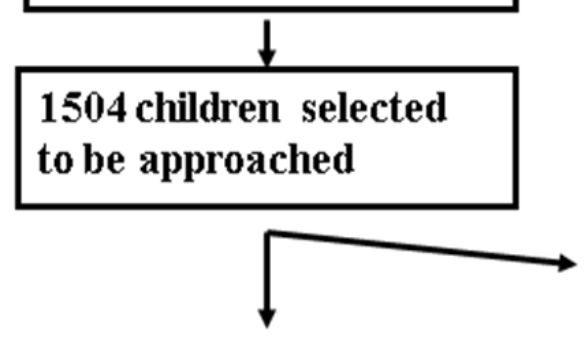

1251 in the original sample
92 error in school list or moved school

99 uncontactable or did not consent 62 excluded due to incomplete data
139 have missing data on one or more risk factors

1112 used in crosssectional analysis

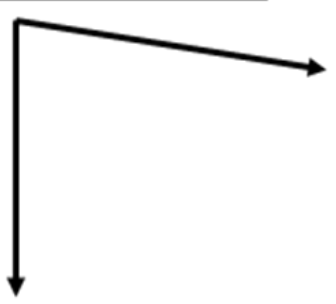

760 followed up and used in prospective analysis

453 not followed up, of whom:

122 moved

108 no trace at address given

82 inadequate address

34 no information

5 opt out

1 died 


\begin{abstract}
Measures
Measurement of child mental health: The Strengths and Difficulties Questionnaire (SDQ) is a 25-item questionnaire with robust psychometric properties, which can be administered to parents, teachers and children over the age of 11 . It provides a dimensional score of a child's psychiatric symptoms and their impact, and includes subscales relating to emotional, hyperactive and behavioral problems (Goodman, 1997; Goodman, 2001). It has been validated and used widely, in high-, middle- and lowincome countries (Eur Child Adolesc Psychiatry, 2004). In a neighboring Brazilian municipality, the SDQ was translated, back-translated and shown to be predictive of the presence or absence of psychiatric disorder (Fleitlich and Goodman, 2001). The SDQ was administered both initially and at follow-up to parents, teachers and (for children aged 11 or over) the children themselves.
\end{abstract}

The Development and Well-Being Assessment (DAWBA) is a multi-informant semistructured interview which trained lay interviewers administer, and which experienced child psychiatrists use to assign psychiatric diagnoses based on DSM-IV criteria (American Psychiatric Association, 1994). The DAWBA consists of a mixture of closed and open questions about child psychiatric symptoms and their impact (i.e. resultant distress and social impairment) (Goodman et al., 2000).. It is administered to parents and teachers, as well as to young people themselves once they are over the age of 11 . The Portuguese version of the DAWBA has been demonstrated to be a valid and reliable tool in children of Southeast Brazil (Fleitlich-Bilyk and Goodman, 2004). The DAWBA was administered in the initial cross-sectional study by psychology or social sciences graduates who were trained and supervised by BFB and RG, who are child psychiatrists. The DAWBA was not repeated at follow-up.

Measures of Risk Factor: Risk factors were only measured in the initial cross-sectional study. In addition to the child's age and sex, extensive information was also collected on the biological, psychological, family, school and community risk factors described below.

- Family demography - Race (White, Black, Mixed, Asian); Religion (Catholic, Other - mostly Evangelical); Whether either parent was a migrant from outside southeast Brazil

- Family socio-economic circumstances - Socio-geographic group, using private, rural or urban school attendance (previously established as a valid marker for membership of the affluent middle-class, rural poor and urban poor respectively (Fleitlich-Bilyk, 2002)); Family affluence calculated from a 20-point questionnaire about number of material possessions, widely used in commercial surveys (Associação Brasileira de Empresas de Pesquisa, 1996); Maternal education ('illiterate', 'primary schooling', 'secondary schooling', 'university education').

- Family composition - Living with both biological parents vs. living in a nontraditional family, primarily step- and lone parent families; Number of siblings; Number of other people living in the household; Three-generational household

- Parental social resources - Parent report of whether they receive social support

- Substance abuse in family - Alcohol abuse; Drug abuse (generally cannabis). 
- Community social capital, individual report; Parent report of 1) whether area is dangerous and 2) whether neighbors are helpful in the area.

- Community social capital, area average; Average parental report from all parents of children in a particular school of 1) level of danger and 2) neighbors' helpfulness in an area respectively. School thereby acted here as a proxy for area of residence.

- Schools' characteristics - Average frequency of bullying for each school, calculated by averaging across schools parent and teacher reports for whether individual children were being bullied.

- Parent's childrearing attitudes - Beliefs on the use of 1) physical punishment 2) reward and 3) supervision, in bringing up children

- Parental stress (anxiety/ depression) - Parent's score on the Self Reporting Questionnaire (SRQ), a 20-point instrument measuring depression and anxiety which has been shown to be valid and reliable in Brazil (Mari and Williams, 1985).

- Marital violence - Child has seen marital violence

- Churchgoing - Whether the child went to church at least once a week

- Nutritional status - Child's age-adjusted body mass index (BMI).

- Child's general health - 'excellent'/'good' vs. 'fair'/‘bad'/ very bad', according to parental report.

- Harsh physical punishment - Child has been beaten with a belt, stick etc

- Child's IQ - an IQ-like score was generated from age-appropriate vocabulary and mathematics tests. Items for this test were selected from a longer battery of words and calculations following piloting in a group of Brazilian children of normal intelligence. Items were selected to generate tests of graded difficulty whose sum scores were normally distributed for each year group within the 7-14 age band. The vocabulary and maths subscores were z-transformed (to give them equal weight) and added to each other. In the current sample, the mean score was unrelated to age and gender.

- Learning difficulties - Having repeated a school year

Apart from height, weight and IQ, all risk variables were based on information provided by a structured interview with parents (available from the authors on request), largely derived from items previously used in Brazil or elsewhere. The interview on risk factors had previously been piloted for acceptability and comprehensibility in a nearby municipality (Fleitlich and Goodman, 2001).

\section{Statistical Analysis}

All tests performed were two-tailed. The outcome measures of child mental health in our analysis were: the presence or absence of a psychiatric (DAWBA) diagnosis at baseline; Total Difficulty SDQ scores as a dimensional measure at both time points; and SDQ scores for specific types of psychopathology (the emotional, behavioral and hyperactivity subscales of the SDQ) at baseline. The Generalized Linear Latent and Mixed Models (GLLAMM) component of STATA 9.0 was used to combine information from parent, teacher and child SDQs to create a single outcome variable ("Combined" scores). For the analysis of the longitudinal data, we used linear regression to predict each individual's Time 2 Combined Total Difficulty Score on the basis of their Time 1 Combined Total Difficulty Score. Subtracting the observed score from the expected score gave the 
residual scores or 'unexplained change' in Time 2 psychopathology, which was then used as our outcome variable in multivariate analyses.

For all analyses, we took account of the clustering of children in the survey (by school) and stratification (by private, rural and urban school types) using the svyset command in STATA version 9.0. Univariate logistic (for the DSM-IV outcomes) and linear (for the SDQ outcomes) regression analyses allowed us to identify risk factors which reached our criterion $(\mathrm{p}<0.1)$ for being candidate risk factors in multivariate model building. We chose a priori to include any marginal risk factors for consideration in multivariate analysis in case they had significant effects that were being masked (negative confounding), though in fact all variables retained in multivariate models were significant $(\mathrm{p}<0.5)$ in univariate analyses, and most were highly significant $(\mathrm{p}<0.01)$.

To minimize the risk of subset effects when comparing cross-sectional models containing different risk factors, a stable dataset of 1112 individuals (89\% of the 1251 recruited in the survey) was then created which had full data for DAWBA diagnosis, for Time 1 SDQ dimensions, and all variables which univariate analyses suggested might be important risk factors, and this was used for all univariate and multivariate analyses.

In multivariate analyses, stepwise logistic regression was used for predicting psychiatric diagnosis, and stepwise linear regression for SDQ outcomes. Collinearity between risk factors was usually low (under 0.4 ), and never prohibitively high $(>0.7)$; the highest value observed was 0.6 between affluence and maternal education. In building multivariate models, age and gender were identified as a priori confounders and were always included in all models. Similarly, when looking separately at the emotional, behavioral or hyperactive subscales of psychopathology (i.e. using these subscales as our dependent variables), we always controlled for the two other subscales in order to take account of the substantial comorbidity in this sample (Fleitlich-Bilyk and Goodman, 2004).

\section{$\underline{\text { Results }}$}

Of the 1251 children assessed at baseline, full data on risk factors was available for 1112 individuals $(89 \%)$. Children with missing data did not differ from children with complete data in terms of their mental health, but were more likely to be from non-traditional families (Odds ratio (OR) 1.73, 95\% CI 1.13 - 2.67) and to be from areas with a higher average danger rating (OR 1.34 per standard deviation increase, 95\% CI $1.16-1.55$ ). There was no evidence that children with missing risk factor data differed in their mental health from children with full data. The mean age of the 1112 children with full data was 10.45 years (SD 2.3 years) and $53 \%$ of them were boys (588 out of 1112 ). $20 \%$ of the children were from private schools, $22 \%$ from rural schools and $58 \%$ from urban schools. According to parental identification, $71 \%$ of the children were White, $6 \%$ Black, $23 \%$ mixed race and $0.5 \%$ Asian. $21 \%$ of the children's mothers were illiterate, $52 \%$ had attended grade school only, $16 \%$ had attended high school only and $11 \%$ had attended university. 
At three-year follow-up, at least one complete SDQ was obtained for 760 of the 1112 children for whom there is full risk factor data at Time 1, representing a response rate of $68 \%$. As was the case for children with missing data in Time 1, multivariate modeling suggested that children lost to follow-up were more likely to living in a non-traditional family (OR 1.90, 95\% CI $1.37-2.64$ ) and to come from areas with a higher average danger rating (OR 1.34 per standard deviation increase in average danger, 95\% CI 1.17 1.53). After adjusting for these variables, there was no evidence that loss to follow-up was differential with regards to child's mental health at Time 1.

Eight of the 29 potential risk factors described in the methods section were not significant even in univariate analyses: religion; any migrant parent; three-generational household; parental report of neighbor's helpfulness; average area report of neighbor's helpfulness; parent attitudes to rewards; parent attitudes to supervision; child's churchgoing. A further 11 variables were significant in univariate analyses but not in any of the multivariate analyses: race; socio-geographic group; family affluence; number of siblings; number of people living in the household; drug abuse; parent report of whether area is dangerous; average school bullying; parent attitudes to physical punishment; marital violence; child's body mass index.

The variables which did remain in our multivariate cross-sectional analyses for the total psychopathology outcome measures are summarized in Table 1. As a guide to interpretation, a variable increases the risk of poor mental health if the odds ratio is greater than 1.0 or the standardized regression coefficient is positive. Conversely, an odds ratio of less than 1.0 or a negative standardized regression coefficient identifies a variable which decreases the risk of poor mental health, i.e. a protective factor. As can be seen, the model using Combined Total Difficulty score as an outcome produces similar results to that using psychiatric diagnosis. Both models show that poor mental health in the child was associated with male gender, living in a non-traditional family, higher parental stress, poor general health, experiencing harsh physical punishment and lower IQ (i.e. higher IQ is protective). There was no evidence that different types of nontraditional family differed in their association with child mental health. 
Table 1: Risk factors and overall psychopathology $(\mathrm{N}=1112)$ at Time 1

\begin{tabular}{|c|c|c|c|c|c|}
\hline \multirow[t]{3}{*}{$\begin{array}{l}\text { Risk Factor } \\
\text { (measured at Time 1) }\end{array}$} & \multirow{2}{*}{$\begin{array}{c}\text { Psychiatric } \\
\text { disorder } \\
\text { (DAWBA } \\
\text { diagnosis) (odds } \\
\text { ratios, with } \\
\text { 95\% CI's) } \\
\end{array}$} & \multicolumn{4}{|c|}{$\begin{array}{c}\text { Total difficulty SDQ score, Time } 1 \\
\text { (standardized regression coefficients, with } 95 \% \text { CI's) }\end{array}$} \\
\hline & & $\begin{array}{l}\text { Combined } \\
\text { report }\end{array}$ & Parent report & Teacher report & Self report \\
\hline & $N=1112$ & $\mathrm{~N}=1112$ & $\mathrm{~N}=1112$ & $\mathrm{~N}=1063$ & $N=550$ \\
\hline Male gender & $\begin{array}{l}1.56(1.03- \\
2.33)^{*}\end{array}$ & $\begin{array}{l}0.14(0.06- \\
0.23)^{* *}\end{array}$ & $\begin{array}{l}0.13(0.06- \\
0.20)^{* * * *}\end{array}$ & $\begin{array}{l}0.36(0.24- \\
0.49)^{* * *}\end{array}$ & $\begin{array}{l}-0.19(-0.43- \\
0.05)\end{array}$ \\
\hline Age (per year increase) & $\begin{array}{l}1.01(0.91- \\
1.12)\end{array}$ & $\begin{array}{l}-0.02(-0.05- \\
0.00)\end{array}$ & $\begin{array}{l}-0.03(-0.05-- \\
0.01)^{*}\end{array}$ & $\begin{array}{l}0.04(0.00- \\
0.07)^{*}\end{array}$ & $\begin{array}{l}-0.05(-0.13- \\
0.02)\end{array}$ \\
\hline Non-traditional family & $\begin{array}{l}2.30(1.58- \\
3.32)^{* * *}\end{array}$ & $\begin{array}{l}0.22(0.08- \\
0.36)^{* *}\end{array}$ & $\begin{array}{l}0.14(0.00- \\
0.28)^{*}\end{array}$ & $\begin{array}{l}0.30(0.18- \\
0.42)^{* * *}\end{array}$ & $\begin{array}{l}0.36(0.22- \\
0.51)^{* * *}\end{array}$ \\
\hline Alcohol abuse in family & & & & & $\begin{array}{l}0.26(0.09- \\
0.43)^{* *}\end{array}$ \\
\hline $\begin{array}{l}\text { Parent reports good social } \\
\text { support }\end{array}$ & & & & $\begin{array}{l}-0.13(-0.25-- \\
0.01)^{*}\end{array}$ & \\
\hline $\begin{array}{l}\text { Area with a high average } \\
\text { danger rating - change per SD } \\
\text { increase }\end{array}$ & & $\begin{array}{l}0.15(0.03- \\
0.26)^{*}\end{array}$ & $\begin{array}{l}0.15(0.05- \\
2.50)^{* *}\end{array}$ & & $\begin{array}{l}0.11(0.01- \\
0.22)^{*}\end{array}$ \\
\hline $\begin{array}{l}\text { Parental stress - change per } \\
\text { SD increase in Self Reporting } \\
\text { Questionnaire (see methods } \\
\text { section) }\end{array}$ & $\begin{array}{l}1.67(1.38- \\
1.98) * * *\end{array}$ & $\begin{array}{l}0.24(0.20- \\
0.29)^{* * *}\end{array}$ & $\begin{array}{l}0.28(0.23- \\
0.33)^{* * *}\end{array}$ & & $\begin{array}{l}0.07(0.00- \\
0.15)^{*}\end{array}$ \\
\hline Poor general health in the child & $\begin{array}{l}2.31(1.40- \\
3.81)^{* *}\end{array}$ & $\begin{array}{l}0.27(0.07- \\
0.47)^{* *}\end{array}$ & $\begin{array}{l}0.32(0.08- \\
0.55)^{*}\end{array}$ & & \\
\hline Harsh physical punishment & $\begin{array}{l}2.14(1.14- \\
4.01)^{*}\end{array}$ & $\begin{array}{l}0.37(0.14- \\
0.59)^{* *}\end{array}$ & $\begin{array}{l}0.40(0.17- \\
0.63)^{* *}\end{array}$ & & \\
\hline $\begin{array}{l}\text { Child's IQ score - change per } \\
\text { SD increase }\end{array}$ & $\begin{array}{l}0.81(0.70- \\
0.95)^{*}\end{array}$ & $\begin{array}{l}-0.08(-0.15-- \\
0.01)^{*}\end{array}$ & & $\begin{array}{l}-0.17(-0.24-- \\
0.10)^{* * *}\end{array}$ & \\
\hline Child has repeated a year & & $\begin{array}{l}0.21(0.05- \\
0.37)^{*}\end{array}$ & & $\begin{array}{l}0.43(0.22- \\
0.65) * * *\end{array}$ & \\
\hline
\end{tabular}

$*=(0.01<\mathrm{p}<0.05), * *=(0.001<\mathrm{p}<0.01), * * *=(\mathrm{p}<0.001)$, missing cells represent risk factors dropped from that model because they were not significant.

The results of subscale specific analyses for the combined SDQ scores in the crosssectional data are reported in Table 2. The variables independently associated with emotional symptoms are female gender, high parental stress and poor general health. The variables associated with behavioral problems are living in a non-traditional family, alcohol abuse in the family, higher parental stress and harsh physical punishment. The factors associated with hyperactivity and inattention are male gender and lower IQ. Thus there is considerable difference between risk factors for different subscales of psychopathology, with the only case of overlap being that of parental stress. 
Table 2: Risk factors and specific psychopathology $(\mathrm{N}=1112)$ at Time 1

\begin{tabular}{|l|l|l|l|}
\hline $\begin{array}{l}\text { Risk Factor } \\
\text { (measured at Time 1) }\end{array}$ & \multicolumn{3}{|c|}{$\begin{array}{c}\text { Combined SDQ scores, Time 1 } \\
\text { (standardized regression coefficient, with 95\% CIs) }\end{array}$} \\
\hline & Emotional subscale & Behavioral subscale & Hyperactivity subscale \\
\hline Male gender & $-0.32(-0.43--0.21)^{* * *}$ & $0.04(-0.06-0.13)$ & $0.29(0.19-0.38)^{* * *}$ \\
\hline Age (per year increase) & $0.01(-0.02-0.03)$ & $-0.02(-0.04-0.00)$ & $0.00(-0.03-0.02)$ \\
\hline Non-traditional family & & $0.21(0.08-0.34)^{* *}$ & \\
\hline Alcohol abuse in family & & $0.17(0.04-0.31)^{*}$ & \\
\hline $\begin{array}{l}\text { Parental stress - change per } \\
\text { SD increase in Self Reporting } \\
\text { Questionnaire (see methods } \\
\text { section) }\end{array}$ & $0.13(0.06-0.19)^{* * *}$ & $0.15(0.11-0.18)^{* * *}$ & \\
\hline $\begin{array}{l}\text { Poor general health in the } \\
\text { child }\end{array}$ & $0.18(0.03-0.40)^{*}$ & & \\
\hline Harsh physical punishment & & & \\
\hline $\begin{array}{l}\text { Child's IQ score }- \text { change per } \\
\text { SD increase }\end{array}$ & & & $-0.34(0.12-0.55)^{* *}$ \\
\hline
\end{tabular}

$*=(0.01<\mathrm{p}<0.05), * *=(0.001<\mathrm{p}<0.01), * * *=(\mathrm{p}<0.001)$, missing cells represent risk factors dropped

from that model because they were not significant.

The correlation between Time 1 and Time 2 Combined Total Difficulty SDQ scores was 0.49 . Table 3 shows that only three factors - younger age, lower maternal education and lower child's IQ - were multivariate predictors for worse mental health at Time 2 independent of their mental health at Time 1. That leaves five factors that were multivariate predictors cross-sectionally (Table 1) but not longitudinally (Table 3). Of these, parental stress and harsh physical punishment were significant risk factors in univariate analyses, but dropped out with the inclusion of maternal education in multivariate models. Area danger, poor general health and repeating a year at school were not significant even in univariate analyses. In forced-entry regression analyses which included all variables which were independent predictors at either Time 1 or Time 2 , the pattern of results shown in Tables 1 and 3 persisted. In particular, factors significant in Table 1 but not Table 3 had effect sizes close to zero (results available on request from the authors). Thus the failure of cross-sectional factors to remain in the prospective model does not appear to be due to reduced statistical power.

Table 3: Time 1 risk factors and Time 2 adjusted psychopathology $(N=760)$

\begin{tabular}{|l|l|}
\hline $\begin{array}{l}\text { Risk Factor } \\
\text { (measured at Time 1) }\end{array}$ & $\begin{array}{l}\text { Residuals of Combined SDQ scores, Time } \\
\text { 2, adjusted for Time 1 scores (standardized } \\
\text { regression coefficients, with 95\% CI's) }\end{array}$ \\
\hline & \\
\hline Male gender & $-0.09(-0.22-0.06)$ \\
\hline Age (per year increase) & $-0.05(-0.08--0.03)^{* * *}$ \\
\hline $\begin{array}{l}\text { Maternal education }- \text { change per } \\
\text { level }\end{array}$ & $-0.21(-0.29--0.13)^{* * *}$ \\
\hline $\begin{array}{l}\text { Child's IQ score }- \text { change per SD } \\
\text { increase }\end{array}$ & $-0.09(-0.15--0.02)^{* *}$ \\
\hline$*=(0.01<\mathrm{p}<0.05), * *=(0.001<\mathrm{p}<0.01)$, & $* * *=(\mathrm{p}<0.001)$. \\
\hline
\end{tabular}




\section{$\underline{\text { Discussion }}$}

In this study of Brazilian 7-14 year olds recruited from a diverse range of sociogeographic environments, greater psychopathology was associated cross-sectionally with living in a dangerous area, living in a non-traditional family, parental stress, harsh physical punishment, poor general health in the child, low IQ, having repeated a year at school and male gender. Marked differences in risk factors were observed for different types of psychopathology: emotional symptoms were associated with parental stress, poor general health and female gender; behavioral problems were associated with living in a non-traditional family, family alcohol abuse, parental stress and harsh physical punishment; hyperactivity was associated with low IQ and male gender. Psychological difficulties were moderately persistent across time, with a correlation of around 0.5 after 3 years. Prospectively, younger age, lower maternal education and lower child's IQ predicted a worse prognosis for mental health even after adjusting for the initial level of psychopathology.

These findings generally replicate those of the British Child and Adolescent Mental Health Surveys (B-CAMHS) which used identical measures of psychopathology, as well as broadly replicating studies from other low- and middle-income countries which used different measures of psychopathology. Females are at greater risk of emotional problems and males at greater risk of externalizing problems, a pattern familiar across the world (Canino et al., 2004; Ford et al., 2004; Hackett and Hackett, 1999). The consistent protective effect of higher child IQ also replicates an effect which was seen in B-CAMHS (Ford et al., 2004) and which has consistently been reported in other studies from lowand middle-income countries (Hackett and Hackett, 1999). Less consistent with previous findings (Meltzer et al., 2003) was the protective effect of older age in the prospective analyses, which resulted from the increase in symptoms with age being steeper in younger children than in older children (for whom symptom scores flattened off).

As in B-CAMHS, a relatively wide range of family variables and adverse social conditions are linked to conduct and (to a lesser extent) emotional disorders, while only a limited number of child-level variables show a consistent association with hyperactivity (Ford et al., 2004). The importance of living in a non-traditional family as a risk factor for poor child mental health, and its particular association with behavioral problems, replicates findings B-CAMHS (Ford et al., 2004), although differing somewhat from findings in Puerto Rico which suggested that living with unmarried parents was particularly associated with emotional problems (Canino et al., 2004). Many previous studies have also reported a strong association observed between physical punishment and mental health problems, particularly conduct disorders (Fleitlich and Goodman, 2001; Ford et al., 2004; Vitolo et al., 2005).

The association between poor physical health and poor mental health, particularly emotional problems, has also been observed not only by us but by many other studies (Ford et al., 2004; Hackett and Hackett, 1999). What is particularly interesting about our findings is that although we found poor general health in the child was a strong and significant multivariate predictor at Time 1, this disappeared at Time 2 even in univariate 
analyses. One possibility is that poor general health is predominantly a result and not a cause of the distress and behavioral problems associated with child psychopathology, in line with previous ecological evidence (Hackett et al., 1999).

Stress or mental illness in the parents has been widely found to be a powerful risk factor for psychopathology in children (Ford et al., 2004; Hackett and Hackett, 1999; Vitolo et al., 2005), including in our own preliminary work in Brazil (Fleitlich and Goodman, 2001). In our study, the association between parental stress and child mental health is evident from both parent- and self-report, but stronger in the parent. The stronger association with parent- rather than self-report suggests the finding may be partly an artifact of a well-recognized rater bias that leads stressed parents to rate their children's mental health more negatively (Boyle and Pickles, 1997a; Boyle and Pickles, 1997b). Nevertheless, the fact that the association is seen with self-report too suggests that the effect is real, albeit exaggerated as judged by parent report. The absence of a similar effect according to teacher report suggests that the association may partly be situational, with children being more distressed or badly behaved at home with the stressed parent than at school.

Most studies in low- and middle-income countries have found lower parental education to be associated with more psychiatric disorder (Hackett and Hackett, 1999). In our study, maternal education did not remain in any of the multivariate cross-sectional models, but was one of the few longitudinal predictors. This was unexpected, but may be because maternal education is a stable predictor of a host of relevant risk factors, including parental stress or punitive parenting behaviors. Given that $85 \%$ of our parent informants were mothers, parental stress at follow-up may have been better predicted by the mother's educational level 3 years earlier than by her stress level 3 years earlier.

\section{Limitations}

The study upon which this analysis is based has many important strengths, including its large sample size, representative sampling frame, high response rate and the inclusion of a longitudinal as well as cross-sectional component. The findings were reassuringly similar whether psychopathology was assessed categorically or dimensionally and whether multi-informant information was combined by expert clinical judgment or by mathematical methods.

Nevertheless, in interpreting our findings it is important to take account of this study's limitations. As both missing data and loss to follow-up were associated with living in a dangerous area and in a non-traditional family, it is plausible that these children lost to analysis constitute a group at particularly high risk. Having said this, it is reassuring that those children with missing data did not appear to differ from those children with full data in terms of psychopathology, suggesting that loss from analysis is unlikely to have introduced a major bias.

Another important limitation is that the reliability and validity of many of our measures of risk factors have not been established in Brazil. In many cases, the unvalidated questions had high face validity (e.g. for gender, race, family size, church attendance, 
perceptions of neighbourhood danger or helpfulness). Others of our measures give more cause for concern as potentially creating biased findings. Our measures of marital violence and harsh physical punishment have not been tested against more detailed measures; this leaves open the possibility that their association with child psychopathology in this study and the pilot study (Fleitlich and Goodman, 2001) says more about the type of families willing to admit to these practices than about the effect of the practices per se. Our measures of child IQ and social capital (average neighbourhood danger, helpfulness and bullying) were developed for this study, and have yet to be validated. In the case of IQ, the fact that it is a predictor both cross-sectionally and longitudinally suggests that it is capturing something meaningful. By contrast, the lack of predictive power of the social capital variables may reflect the weakness of our measures, rather than the irrelevance of social capital.

This study is also limited by what we did not measure. For example, we lack information on adverse life events, which other studies have suggested may be important (Ford et al., 2004; Hackett et al., 1999). Similarly, witnessing marital violence is our only measure of poor family functioning and parental disharmony, which others have shown to be important (Ford et al., 2004; Patel et al., In Press). Finally, one of the most important limitations of this study, is that we had no reassessment of risk factors at follow-up - a deficiency which, we speculate, may have contributed to maternal education replacing parental stress as a predictor at Time 2.

\section{Clinical Implications}

Having previously demonstrated that child mental health problems are frequent in Brazil (Fleitlich-Bilyk and Goodman, 2004), this study shows that they are also persistent, as indexed by a substantial correlation of symptom scores across 3 years. This reinforces the urgent need to make effective treatments widely available.

The main implications of research of this kind, however, lie not in the domain of individual treatment but in informing public health approaches to the prevention of child mental health problems. Given the paucity of research in South America, and indeed in much of the low- and middle-income world, extrapolating from child mental health studies in high-income countries has to date been the only option open to healthcare planners and policy makers. It is therefore reassuring that our findings show many commonalities and no striking differences with research from elsewhere in the world is therefore reassuring.

Priorities for future research are to strengthen and expand our understanding of the risk factors associated with child psychopathology, and also to delineate their causal pathways more precisely in order to identify suitable targets for intervention. Provisionally, our findings suggest that there are multiple risk and protective factors, none of which has more than a moderate effect size (e.g. an odds ratio of under 2.5). This perhaps points to the need to rise to the challenge of targeting multiple risk factors in order to obtain substantial health benefits. On the positive side, the benefits of a successful intervention programme may extend beyond a reduction in psychiatric disorder. Our findings showed 
that similar risk factors were associated with psychiatric diagnoses at the extreme of the population and with dimensional measures of mental health across the entire population. Thus the same sorts of interventions that prevent psychiatric disorders may well improve the mental health of the child population as a whole.

\section{Conflict of interest}

$\mathrm{AG}$ and RG are directors and part-owners of youthinmind, a private company that distributes an electronic version of the DAWBA interview as a free public service for non-profit use in Brazil. The other authors have no financial relationships to disclose.

\section{Acknowledgements}

The cross-sectional and follow-up studies were funded by the Wellcome Trust, which included a salary for BFB as a clinical researcher. Secondary analysis of the data by AG was carried out while she held an MRC studentship. VP is supported by a Wellcome Trust Senior Clinical Research Fellowship in Tropical Medicine.

\section{$\underline{\text { References }}$}

American Psychiatric Association (1994), Diagnostic and Statistical Manual of Mental Disorders, 4th edition (DSM-IV). Washington, DC: American Psychiatric Association.

Associação Brasileira de Empresas de Pesquisa (1996), Critério de Classificação Econômica Brasil. ABEP [formerly ANEP] www.abep.org

Bird HR, Canino G, Rubio-Stipec M, Gould MS, Ribera J, Sesman M, Woodbury M, Huertas-Goldman S, Pagan A, Sanchez-Lacay A, et al. (1988), Estimates of the prevalence of childhood maladjustment in a community survey in Puerto Rico. The use of combined measures. Arch Gen Psychiatry 45: 1120-6

Boyle MH, Pickles A (1997a), Maternal depressive symptoms and ratings of emotional disorder symptoms in children and adolescents. J Child Psychol Psychiatry 38: 981-92

Boyle MH, Pickles AR (1997b), Influence of maternal depressive symptoms on ratings of childhood behavior. J Abnorm Child Psychol 25: 399-412

Canino G, Shrout PE, Rubio-Stipec M, Bird HR, Bravo M, Ramirez R, Chavez L, Alegria M, Bauermeister JJ, Hohmann A, Ribera J, Garcia P, Martinez-Taboas A (2004), The DSM-IV rates of child and adolescent disorders in Puerto Rico: prevalence, correlates, service use, and the effects of impairment. Arch Gen Psychiatry 61: 85-93

Eur Child Adolesc Psychiatry (2004), Special supplement edition on the SDQ in Europe Volume 13, Supplement 1

Fleitlich-Bilyk B (2002), The prevalence of psychiatric disorders in 7-14 year olds in the South East of Brazil, Doctoral Thesis. Thesis. Type, University of London (availablefrombacy@uol.com.br)

Fleitlich-Bilyk B, Goodman R (2004), Prevalence of child and adolescent psychiatric disorders in southeast Brazil. J Am Acad Child Adolesc Psychiatry 43: 727-34 
Fleitlich B, Goodman R (2001), Social factors associated with child mental health problems in Brazil: cross sectional survey. Bmj 323: 599-600

Ford T, Goodman R, Meltzer H (2004), The relative importance of child, family, school and neighbourhood correlates of childhood psychiatric disorder. Soc Psychiatry Psychiatr Epidemiol 39: 487-96

Goodman R (1997), The Strengths and Difficulties Questionnaire: a research note. J Child Psychol Psychiatry 38: 581-6

Goodman R (2001), Psychometric properties of the strengths and difficulties questionnaire. J Am Acad Child Adolesc Psychiatry 40: 1337-45

Goodman R, Ford T, Richards H, Gatward R, Meltzer H (2000), The Development and Well-Being Assessment: description and initial validation of an integrated assessment of child and adolescent psychopathology. J Child Psychol Psychiatry 41: $645-55$

Green H, McGinnity A, Meltzer H, Ford T, Goodman R (2005), Mental health of children and young people in Great Britain, 2004 Palgrave MacMillan

Hackett R, Hackett L (1999), Child psychiatry across cultures. Int Rev Psychiatry 11: 225-35

Hackett R, Hackett L, Bhakta P, Gowers S (1999), The prevalence and associations of psychiatric disorder in children in Kerala, South India. J Child Psychol Psychiatry 40: 801-7

Hackett R, Hackett L, Bhakta P, Gowers S (2000), Life events in a South Indian population and their association with psychiatric disorder in children. Int J Soc Psychiatry 46: 201-7

Mari JJ, Williams P (1985), A comparison of the validity of two psychiatric screening questionnaires (GHQ-12 and SRQ-20) in Brazil, using Relative Operating Characteristic (ROC) analysis. Psychol Med, 15: 651-9

Meltzer H, Gatward R, Corbin T, Goodman R, Ford T (2003), Persistence, onset, risk factors and outcomes of childhood mental disorders London: The Stationery Office

Mullick MS, Goodman R (2005), The prevalence of psychiatric disorders among 5-10 year olds in rural, urban and slum areas in Bangladesh: an exploratory study. Soc Psychiatry Psychiatr Epidemiol 40: 663-71

Patel V, Flisher A, McGorry P (In Press), The mental health of young people: a global public health challenge. The Lancet (commissioned review for Lancet series on adolescent health)

Remschmidt H, Belfer M (2005), Mental health care for children and adolescents worldwide: a review. World Psychiatry 4: 147-53

Vitolo YL, Fleitlich-Bilyk B, Goodman R, Bordin IA (2005), [Parental beliefs and childrearing attitudes and mental health problems among schoolchildren]. Rev Saude Publica 39: 716-24 